\title{
Ablação de Eixos Safénicos com Laser - step to step
}

\author{
Ferreira J. ${ }^{1}$ \\ ${ }^{1}$ Porto Alegre - Brasil. \\ E-mail:drjulioferreira@ibf.med.br
}

Ferreira, J. 2013. Ablaáão de Eixos Safénicos com Laser - step to step, p.29. In: Bastos, Francisco Reis. Anais V Simpósio Internacional de Flebologia [Blucher Medical Proceedings n.1, v.1] São Paulo: Blucher, 2014

http://dx.doi.org/10.5151/medpro-flebo-SIF_10
A recente publicação dos guidelines da Sociedade Americana de Cirurgia Vascular e do American Venous Forum por Peter Gloviczky e colaboradores no JVS, onde as ablações térmicas com Laser e Radiofrequência são classificadas com um Grau de Recomendação 1 e Nivel de Evidência B, parece ter colocado um fim no reinado absoluto que durante mais de um século a Safenectomia exerceu no tratamento de varizes decorrentes de refluxos das veias safenas, e que hoje divide espaço com estas e outras tecnologias que estão sendo introduzidas (Ablações com Vapor de Água, selagem com Cianoacrilato, ablações químicas com espuma etc.).

Conceituados investigadores e renomados serviços trabalham atualmente com todas estas técnicas e o tempo definirá qual o espaço reservado para cada uma delas no tratamento dos eixos safénicos.

O Objetivo desta apresentação não é polemizar sobre se o Laser Endovascular é melhor ou pior do que qualquer uma das técnicas acima descritas e sim, mostrar, passo a passo, a melhor forma de utilizá-lo, e revisar alguns conceitos que são fundamentais para a compreensão desta técnica.

Palavras-chave: laser, IVC, varizes, tratamento de varizes. 